\title{
Pointing movements both impair and improve visuospatial working memory depending on serial position
}

\author{
Clelia Rossi-Arnaud $^{1}$ • Emiddia Longobardi ${ }^{2}$ - Pietro Spataro ${ }^{1}$
}

Published online: 30 March 2017

(C) Psychonomic Society, Inc. 2017

\begin{abstract}
Two experiments investigated the effects of pointing movements on the item and order recall of random, horizontal, and vertical arrays consisting of 6 and 7 squares (Experiment 1) or 8 and 9 squares (Experiment 2). In the encoding phase, participants either viewed the items passively (passive-view condition) or pointed towards them (pointing condition). Then, after a brief interval, they were requested to recall the locations of the studied squares in the correct order of presentation. The critical result was that, for all types of arrays, the effects of the encoding condition varied as a function of serial position: for the initial and central positions accuracy was higher in the passive-view than in the pointing condition (confirming the standard inhibitory effect of pointing movements on visuospatial working memory), whereas the reverse pattern occurred in the final positionsshowing a significant advantage of the pointing condition over the passive-view condition. Findings are interpreted as showing that pointing can have two simultaneous effects on the recall of spatial locations, a positive one due to the addition of a motor code and a negative one due to the attentional requirements of hand movements, with the net impact on serial recall depending on the amount of attention resources needed for the encoding of each position. Implications for the item-order hypothesis and the perceptual-gestural account of working memory are also discussed.
\end{abstract}

Clelia Rossi-Arnaud

clelia.rossi-arnaud@uniroma1.it

1 Department of Psychology, Sapienza University of Rome, Via dei Marsi 78, 00185 Rome, Italy

2 Department of Clinical Psychology, Sapienza University of Rome, Via dei Marsi 78, 00185 Rome, Italy
Keywords Visuospatial working memory · Pointing movements $\cdot$ Serial recall $\cdot$ Symmetry

Decades of research with the dual-task paradigm tell us that movement-based interference tasks (e.g., the tapping task), performed during the encoding and/or the interval phases, have a negative impact upon visuospatial working memory (VSWM; Baddeley \& Lieberman, 1980; Della Sala, Gray, Baddeley, Allamano, \& Wilson, 1999; Klauer \& Stegmaier, 1997; Klauer \& Zhao, 2004; Logie, Zucco, \& Baddeley, 1990; Quinn, 1994; Quinn \& Ralston, 1986; Rossi-Arnaud, Pieroni, \& Baddeley, 2006; Rossi-Arnaud, Pieroni, Spataro, \& Baddeley, 2012; Smyth \& Scholey, 1994; Vandierendonck, Kemps, Fastame, \& Szmalec, 2004; see Quinn, 2008, for a review). To understand the source of this movement-related interference, it is necessary to briefly illustrate the working memory model originally proposed by Baddeley and Hitch (1974) and later revised by Baddeley (2000; see Baddeley, 2012, for an updated review), and the subsequent fractionation of the visuospatial component advanced by Logie (1995). Basically, the latest model of working memory consists of (a) a central executive, which coordinates the operations of the other components; (b) two slave subsystems, the phonological loop and the visuospatial sketchpad, which are responsible for the temporary storage and active manipulation of verbal and visuospatial information, respectively; and (c) an episodic buffer, which is assumed to hold integrated episodes (or chunks) in a multidimensional code, providing the missing link between the contents of working memory, perception, and long-term memory (Baddeley, 2000). More importantly for the present purposes, Logie (1995) hypothesized an additional fractionation of the visuospatial component, which he refers to as visuospatial working memory (VSWM), into a passive $v i$ sual cache, which maintains information about shapes and 
colors, and an active inner scribe, which codes and rehearses the spatial features of studied stimuli in terms of movementbased processes. By this account, the negative effects of interference tasks requiring target-directed movements can be simply understood as a consequence of these tasks occupying the inner scribe and therefore preventing the active rehearsal of spatial information.

In contrast with this overwhelming literature, a few studies reported evidence that movements, and specifically pointing gestures, can have beneficial effects on short-term memory. In Chum, Bekkering, Dodd, and Pratt (2007), in particular, participants were asked to remember two successive spatial arrays consisting of three, four, or five white-filled squares and circles; one array was encoded with pointing movements (participants were asked to tap, on the touch-screen, at the location in which each item was presented), while the other array was encoded with no movements. The results showed that pointedto arrays were recognized significantly better than passively viewed arrays, with the size of the advantage decreasing in a load-dependent manner (being maximum for three-item arrays but nonsignificant for five-item arrays). Chum et al. (2007) proposed that at least two factors could account for such a facilitation. On the one hand, pointing movements might lead participants to adopt a spatially based processing orientation, which in turn improves the encoding of the spatial arrangement of target arrays. Alternatively, pointing might imply a stronger form of egocentric elaboration, which supplements the allocentric elaboration involved in the passive-view condition. Later studies replicated these findings, but additionally demonstrated that when pointing instructions were blocked (that is, when participants pointed to or passively viewed all the items in a given array), pointing toward the to-beremembered locations actually impaired recognition memory (Dodd \& Shumborski, 2009; Rossi-Arnaud, Spataro, \& Longobardi, 2012; Rossi-Arnaud, Spataro, Marques, \& Longobardi, 2015).

Importantly, all of the aforementioned experiments have assessed item memory (typically via recognition tasks), without taking into account the order in which the locations were presented during the study phase. Dodd and Shumborski (2009, p.1246), however, speculated that encoding spatial stimuli via a motor code might facilitate performance in a serial recall task. Such a prediction follows from the notion that the pointing manipulation should lead to the encoding of spatial representations in which the single locations are connected by imagined lines in a sequential path (i.e., path encoding), whereas the passive viewing manipulation should lead to the encoding of visual representations in which individual items are stored as global, integrated objects and shapes (i.e., pattern encoding; Jiang, Olson, \& Chun, 2000; Lecerf \& de Ribaupierre, 2005). Thus, these two manipulations should result in the formation of qualitatively different representations, which are stored and manipulated either in the inner scribe (for movement-based spatial representations) or in the visual cache (for static visual patterns). A direct consequence of this difference is that the probability of observing a significant memory advantage in the pointing condition should be a function of the specific type of retrieval task being employed. In free recall or recognition tests, in which the order of presentation of the studied locations can be ignored, memory performance should be largely dependent on the use of static, visual representations, resulting in a significant advantage of the passive-view condition (Dodd \& Shumborski, 2009; Rossi-Arnaud et al., 2012; Rossi-Arnaud et al., 2015). On the other hand, in serial recall tests, in which participants have to remember the order of presentation of the spatial items, memory performance should rely more heavily on the use of spatial path representations, leading to a significant advantage for the pointing condition. Spataro, Marques, Longobardi, and Rossi-Arnaud (2015) tested the validity of this theoretical prediction in a serial recall task, in which participants pointed to or passively viewed target arrays varying in length from five to eight items, and reproduced the order of presentation on a blank matrix. Unexpectedly, they found that pointing movements continued to impede the recall performance, with the size of the impairment being larger in the initial and central positions than in the final positions.

The present two experiments were aimed at replicating and extending the results illustrated by Spataro et al. (2015). First, these authors reported that the interaction between encoding condition (pointing vs. passive view) and serial position was significant for seven-item arrays, marginal for six-item arrays, and nonsignificant for five- and eight-item arrays. Given the potential theoretical importance of this finding (see later for a discussion of the attentional requirements of VSWM; Allen, Baddeley, \& Hitch, 2014), it is important to provide additional, more convincing data about its significance. Second, RossiArnaud, Spataro, and Longobardi (2012) proposed that pointing movements might interfere with the development and the use of efficient retrieval strategies, such as chunking the spatial sequences into meaningful groups of three to four locations- for example, groups forming familiar configurations, such as geometrical shapes or alphabetical letters (Huntley, Bor, Hampshire, Owen, \& Howard, 2011; Ridgeway, 2006). In the present experiments this hypothesis was tested by presenting not only random arrays (i.e., arrays in which the arrangement of the to-be-remembered items followed no structural regularity), like in Spataro et al. (2015), but also symmetrical (vertical and horizontal) spatial sequences. In particular, we focused on mirror (or bilateral) symmetry, a class of spatial transformations based on the reflection of individual items along a predetermined axis (Rossi-Arnaud, Pieroni, Spataro, \& Baddeley, 2012; Wagemans, 1997). A consistent body of research indicates that symmetrical arrays are recalled significantly better than nonsymmetrical ones, both in healthy individuals (Imbo, Szmalec, \& Vandierendonck, 2009; Kemps, 
2001; Pieroni, Rossi-Arnaud, \& Baddeley, 2011; Rossi-Arnaud et al., 2006; Rossi-Arnaud et al., 2012) and in clinical populations (Cattaneo et al., 2010; Cestari et al., 2013). At least part of this advantage is because symmetrical arrays allow a better use of chunking strategies. More specifically, Kemps (2001) hypothesized that long-term information about the properties of symmetrical arrays is accessed during the process of retrieving spatial locations from VSWM, facilitating their reconstruction when the capacity limits are exceeded. In agreement, Bornstein and Stiles-Davis (1984) found that both children and healthy adults reproduced symmetrical arrays by using an axis-based strategy - that is, retrieving one side of the array and then completing the other side by reflection across the symmetry axis. Thus, if pointing movements interfere with the use of chunking strategies, then the recall of symmetrical sequences should be impaired in the pointing condition, and the size of the impairment should be similar to that observed with random arrays.

\section{Experiment 1}

In Experiment 1, we examined the effects of pointing movements on the recall of six- and seven-item symmetrical (vertical and horizontal) and nonsymmetrical (random) arrays.

\section{Method}

Participants Sixteen students of the University Sapienza of Rome volunteered to participate in Experiment 1. The sample consisted of eight males and eight females, with a mean age of 25.4 years $(S D=2.4)$. All of them had normal or corrected-tonormal vision.

Stimuli A total of 60 arrays containing 25 squares $(2 \mathrm{~cm} \times$ $2 \mathrm{~cm}$ each, with two adjacent squares separated by $1 \mathrm{~cm}$ ), arranged in a regular $5 \times 5$ matrix, were selected from those used by Rossi-Arnaud, Pieroni, and Spataro (2012). The tobe-recalled squares (six or seven) appeared in red, with all other squares presented in black. The configurations formed by the red squares could be random (20 arrays), or bilaterally symmetrical along the vertical (20 arrays) and horizontal (20 arrays) axes (see Fig. 1 for examples). For each type of stimulus, five arrays were randomly assigned to the four experimental conditions formed by the combination between encoding condition (pointing vs. passive-view) and array length (6 vs. 7 items; Smyth \& Scholey, 1994). Within each array, the order of presentation of the red squares was completely random.

Design and procedure Experiment 1 followed a completely repeated 2 (array size: six and seven items) $\times 2$ (encoding condition: pointing vs. passive view) $\times 3$ (stimulus type: random, vertical, horizontal) design.

Each trial comprised a study phase, an interval and a retrieval phase. During the study phase, participants were instructed to remember the locations and the order of presentation of the red squares. The to-be-remembered array was always preceded by a fixation point (a cross at the center of the screen) for $500 \mathrm{~ms}$. Then, the target squares (in red) were presented sequentially for $1 \mathrm{~s}$ each. Presentation was blocked by condition, so that participants performed first all the passive-view trials and then all the pointing trials (we chose this order because it was associated with a better memory performance in the study by RossiArnaud et al., 2012), and by array size, so that participants recalled the shorter arrays always before the longer arrays. On the other hand, the order of presentation of the three types of arrays was counterbalanced across participants, resulting in six different encoding versions. In the pointing trials, participants were instructed to point toward the red squares, by touching their positions on the screen; by contrast, in the passive-view trials they were told to observe the locations of the red squares without moving their hands.

Immediately after the presentation of the last item, there was a pause of $2 \mathrm{~s}$. Then, memory was tested with a serial recall procedure. Participants were given a sheet of paper containing a matrix of 25 blank squares of the same size as that presented on the screen. They were told to recall the order of presentation of the red squares by writing the corresponding numbers inside the squares ( 1 for the first item, 2 for the second item, etc.). The instructions made it clear that participants had to start recall from the first item presented at encoding, and the experimenter ensured compliance with this rule. As in Rossi-Arnaud, et al. (2012), we did not use a touchscreen because we wanted to ensure that any facilitation observed in the pointing condition could not be explained by a motor effect due to the repetition of the same movements at the time of test. The transfer-appropriate-processing theory maintains that memory performance will be increased when
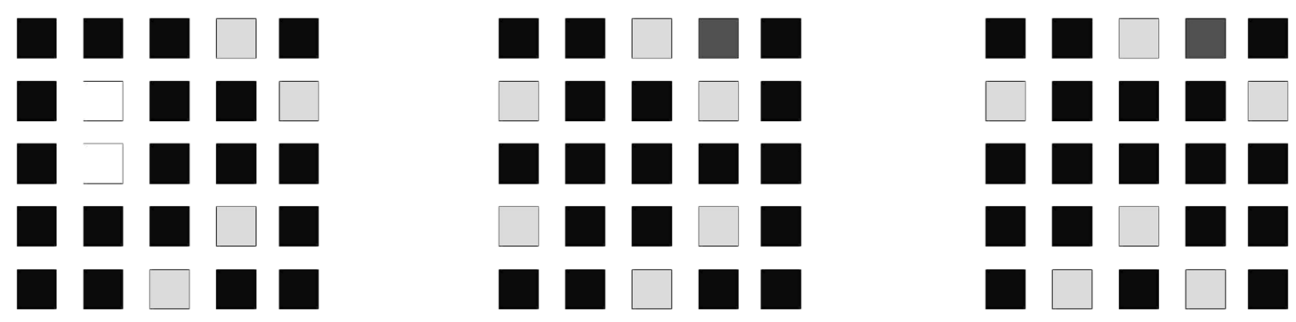

Fig. 1 Examples of the six-item random, horizontal and vertical arrays presented in Experiment 1. Gray-filled squares were shown in red 
the operations performed at encoding are re-engaged at retrieval (Morris, Bransford, \& Franks, 1977). Therefore, the use of a touch screen could have resulted in a spurious facilitation due to the reinstatement of the motor conditions experienced at encoding (see Ouwehand, van Gog, \& Paas, 2016, for discussion).

\section{Results and discussion}

Item memory Item memory (i.e., the mean proportions of input locations correctly recalled, irrespective of the order in which they were retrieved by participants) was examined separately for six- and seven-item arrays (see Table 1). As concerns six-item arrays, data were submitted to a completely repeated 2 (encoding condition: pointing vs. passive view) $\times$ 3 (stimulus type: random, vertical, horizontal) $\times 6$ (serial position) ANOVA, which revealed the following:

a. a main effect of the encoding condition that approached the significance level, $F(1,15)=4.34, M S E=0.058, p=$

Table 1 Experiment 1: Mean proportions of items correctly recalled, as a function of encoding condition, array size and stimulus type. Standard deviations are reported in parentheses

\begin{tabular}{|c|c|c|c|c|}
\hline & \multicolumn{2}{|c|}{ Passive-view condition } & \multicolumn{2}{|c|}{ Pointing condition } \\
\hline & 6-item & 7-item & -item & 7-item \\
\hline \multicolumn{5}{|c|}{ Vertical arrays } \\
\hline Position 1 & $0.91(0.12)$ & $0.75(0.22)$ & $0.72(0.26)$ & $0.53(0.26)$ \\
\hline Position 2 & $0.81(0.24)$ & $0.75(0.18)$ & $0.76(0.23)$ & $0.68(0.27)$ \\
\hline Position 3 & $0.82(0.19)$ & 0.60 & $0.72(0.25)$ & $0.60(0.30)$ \\
\hline Position 4 & $0.60(0.30)$ & $0.63(0.23)$ & $0.68(0.28)$ & $0.51(0.25)$ \\
\hline Position 5 & $0.63(0.28)$ & $0.55(0.28)$ & $0.68(0.29)$ & $0.63(0.31)$ \\
\hline Position 6 & $0.65(0.26)$ & $0.62(0.27)$ & $0.67(0.26)$ & $0.66(0.28)$ \\
\hline Position 7 & --- & $0.55(0.24)$ & --- & $0.73(0.27)$ \\
\hline \multicolumn{5}{|c|}{ Horizontal arrays } \\
\hline Position 1 & $0.76(0$ & 0.8 & 0.67 & $0.71(0.26)$ \\
\hline Position 2 & $0.83(0.18)$ & $0.67(0.24)$ & $0.73(0.23)$ & $0.61(0.27)$ \\
\hline Position 3 & $0.76(0.27)$ & $0.73(0.20)$ & $0.71(0.23)$ & $0.57(0.30)$ \\
\hline Position 4 & $0.67(0.25)$ & $0.53(0.28)$ & $0.66(0.18)$ & $0.55(0.25)$ \\
\hline Position 5 & $0.61(0.25)$ & $0.61(0.26)$ & $0.62(0.25)$ & $0.62(0.31)$ \\
\hline Position 6 & $0.58(0.33)$ & $0.56(0.19)$ & $0.68(0.30)$ & $0.73(0.28)$ \\
\hline Position 7 & --- & $0.58(0.29)$ & --- & $0.68(0.27)$ \\
\hline \multicolumn{5}{|c|}{ Random arrays } \\
\hline Position 1 & $0.82(0.22)$ & $0.62(0.19)$ & $0.71(0.21)$ & $0.51(0.23)$ \\
\hline Position 2 & $0.82(0.17)$ & $0.55(0.25)$ & $0.67(0.20)$ & $0.41(0.23)$ \\
\hline Position 3 & $0.63(0.27)$ & $0.57(0.20)$ & $0.48(0.28)$ & $0.38(0.25)$ \\
\hline Position 4 & $0.48(0.23)$ & $0.56(0.26)$ & $0.43(0.26)$ & $0.41(0.24)$ \\
\hline Position 5 & $0.43(0.27)$ & $0.38(0.30)$ & $0.43(0.26)$ & $0.45(0.21)$ \\
\hline Position 6 & $0.56(0.27)$ & $0.56(0.33)$ & $0.58(0.24)$ & $0.62(0.31)$ \\
\hline Position 7 & --- & $0.56(0.34)$ & --- & $0.66(0.29)$ \\
\hline
\end{tabular}

$.055, \eta_{\mathrm{p}}{ }^{2}=0.23$, indicating that participants tended to recall more locations in the passive-view $(M=0.69)$ than in the pointing condition $(M=0.65)$;

b. a significant main effect of stimulus type, $F(2,30)=9.02$, $M S E=0.102, p=.001, \eta_{\mathrm{p}}{ }^{2}=0.38$, indicating that random arrays $(M=0.59)$ were recalled worse than vertical $(M=$ $0.73, p=.004)$ and horizontal arrays $(M=0.69, p=.009)$, whereas the two symmetrical arrays did not differ between them $(p=1.00)$;

c. a significant main effect of serial position, $F(5,75)=$ 10.18, MSE $=0.073, p<.001, \eta_{\mathrm{p}}{ }^{2}=0.40$ : post hoc comparisons, with the Bonferroni adjustment, demonstrated a primacy effect, with the first location being recalled better than the fourth and fifth locations $(p=.001$ and $p=.009$, respectively), but no recency effect (the last position was recall no better than the fifth, fourth, and third positions: $p$ $=1.00$ in all cases);

d. a significant two-way interaction between stimulus type and serial position, $F(10,150)=2.92, M S E=0.035, p=$ $.002, \eta_{\mathrm{p}}{ }^{2}=0.16$ : a follow-up analysis of simple effects revealed that the serial position effect was significant for random arrays, $F(5,11)=17.86, p<.001, \eta_{\mathrm{p}}{ }^{2}=0.89$, tended to significance for horizontal arrays, $F(5,11)=$ 2.93, $p=.064, \eta_{\mathrm{p}}{ }^{2}=0.57$, and was nonsignificant for vertical arrays, $F(5,11)=1.80, p=.19, \eta_{\mathrm{p}}{ }^{2}=0.45$; and

e. a significant two-way interaction between encoding condition and serial position, $F(5,75)=3.97, M S E=0.035, p$ $=.003, \eta_{\mathrm{p}}{ }^{2}=0.21$ : a follow-up analysis of simple effects indicated that memory was better in the passive-view than in the pointing condition for the first three serial positions, $F(1,15)=13.87, p=.002, \eta_{\mathrm{p}}{ }^{2}=0.48 ; F(1,15)=7.50, p=$ $.015, \eta_{\mathrm{p}}{ }^{2}=.33 ; F(1,15)=9.31, p=.008, \eta_{\mathrm{p}}{ }^{2}=0.38$, whereas there were no significant differences for the other positions, $F(1,15)=0.04, p=.83, \eta_{\mathrm{p}}{ }^{2}=0.003 ; F(1,15)=$ $0.33, p=.57, \eta_{\mathrm{p}}{ }^{2}=0.02 ; F(1,15)=0.75, p=.39, \eta_{\mathrm{p}}{ }^{2}=$ 0.05 .

For 7-item arrays, a similar ANOVA showed only the following:

a. a significant main effect of stimulus type, $F(2,30)=$ $13.13, M S E=0.080, p<.001, \eta_{\mathrm{p}}{ }^{2}=0.47$, indicating that random arrays $(M=0.52)$ were recalled worse than vertical $(M=0.63, p<.001)$ and horizontal arrays $(M=0.65, p$ $=.006)$, whereas the two symmetrical arrays did not differ between them $(p=1.00)$;

b. a significant two-way interaction between encoding condition and serial position, $F(6,90)=6.67, M S E=0.045, p$ $<.001, \eta_{\mathrm{p}}{ }^{2}=0.31$ : a follow-up analysis of simple effects indicated that item memory was better in the passive-view than in the pointing condition for the first and fourth serial positions, $F(1,15)=33.34, p<.001$ and $F(1,15)=11.66$, $p=.004$, whereas it was better in the pointing condition 
for the last serial position, $F(1,15)=5.74, p=.03, \eta_{\mathrm{p}}{ }^{2}=$ 0.28 . The advantages of the passive-view condition for the second and third positions and of the pointing condition for the last to second position approached the significance level $(p=.080, p=.050$, and $p=.077$, respectively).

Order memory Order memory was also examined separately for six- and seven-item arrays (see Fig. 2). As concerns sixitem arrays, the proportions of items recalled in their correct serial positions were submitted to a completely repeated 2 (encoding condition: pointing vs. passive view) $\times 3$ (stimulus type: random, vertical, horizontal) $\times 6$ (serial position) ANOVA, which showed the following:

Order Memory - Random Arrays

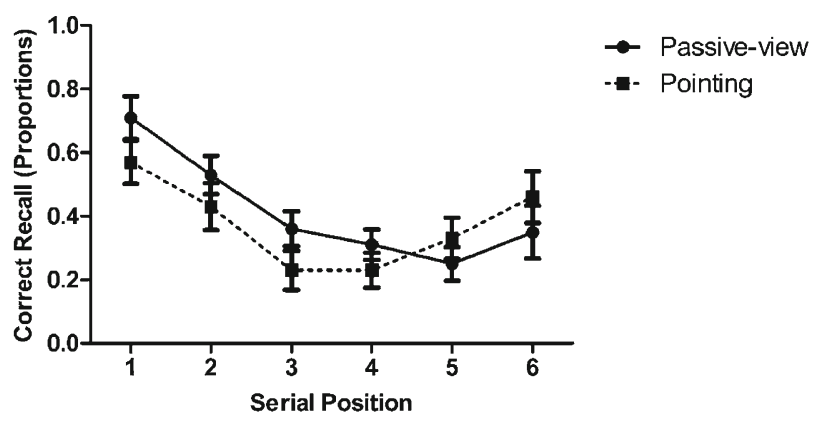

Order Memory - Horizontal Arrays

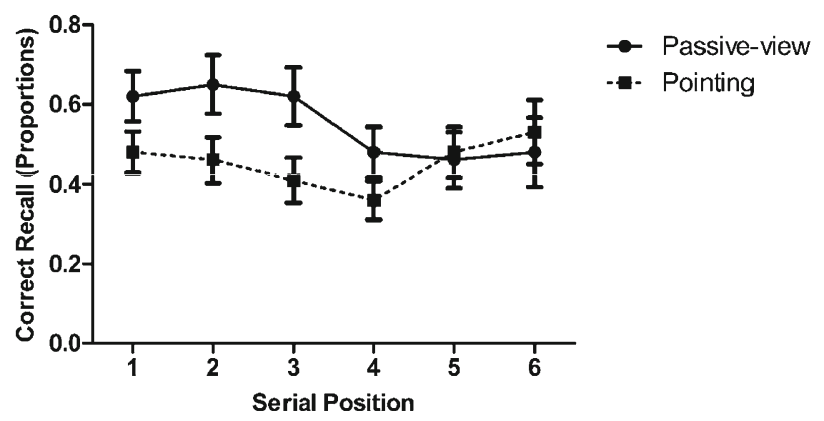

Order Memory - Vertical Arrays

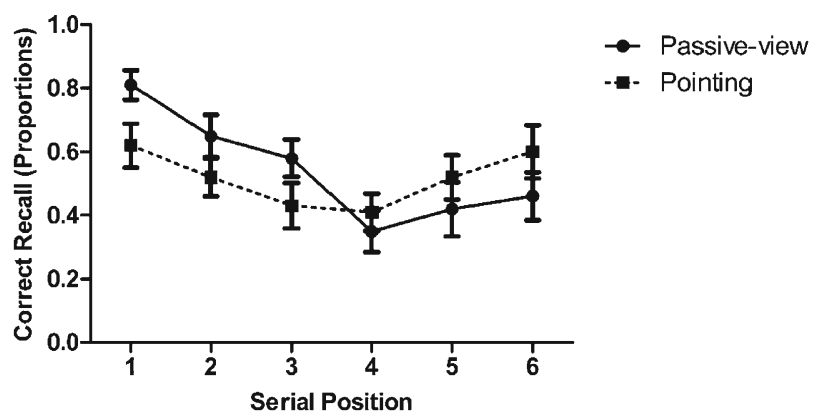

a. a significant main effect of encoding condition, $F(1,15)=$ $6.20, M S E=0.070, p=.025, \eta_{\mathrm{p}}{ }^{2}=0.29$, indicating that participants recalled more locations in the passive-view $(M=0.51)$ than in the pointing condition $(M=0.45)$;

b. a significant main effect of stimulus type, $F(2,30)=$ $12.03, M S E=0.079, p<.001, \eta_{\mathrm{p}}{ }^{2}=0.45$, indicating that random arrays $(M=0.40)$ were recalled worse than vertical $(M=0.51, p<.001)$ and horizontal arrays $(M=0.53, p$ $=.006)$, with no difference between the two symmetrical arrays $(p=1.00)$;

c. a significant main effect of Serial Position, $F(5,75)=$ $8.17, M S E=0.116, p<.001, \eta_{\mathrm{p}}{ }^{2}=0.35$ : post hoc comparisons, with the Bonferroni adjustment, demonstrated a strong primacy effect, with the first location being recalled better than the second, third, fourth, and fifth locations ( $p$ $=.021, p<.001, p<.001, p=.027)$, but no recency effect
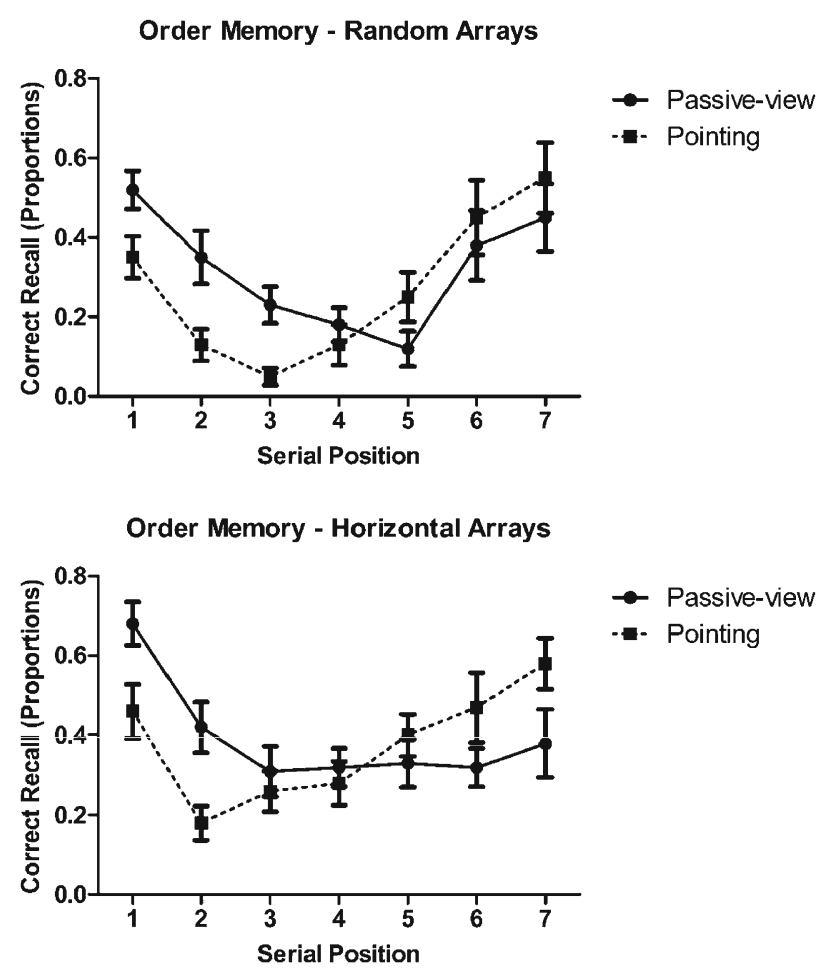

Order Memory - Vertical Arrays

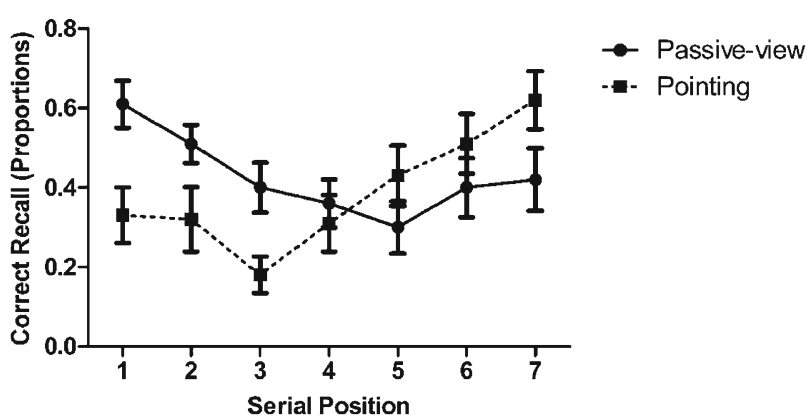

Fig. 2 Experiment 1: Mean proportions of items recalled in their correct serial positions for six-item and seven-item arrays, as a function of stimulus type and encoding condition. Bars represent standard errors 
(the last item was recalled no better than the fifth to first items: $p=.15, p=.57, p=1.00, p=1.00, p=.63$ );

d. a significant two-way interaction between stimulus type and serial position, $F(10,150)=2.55, M S E=0.041, p=$ $.007, \eta_{\mathrm{p}}{ }^{2}=0.15$ : a follow-up analysis of simple effects revealed that the effect of serial position (i.e., the recall advantage of the first position) was more pronounced with random than with vertical and horizontal arrays, although it reached the significance level with all types of stimuli$F(5,11)=12.55, p<.001, \eta_{\mathrm{p}}{ }^{2}=0.85$ for random arrays, $F(5,11)=7.07, p=.003, \eta_{\mathrm{p}}{ }^{2}=0.76$ for horizontal arrays, and $F(5,11)=5.99, p=.006, \eta_{\mathrm{p}}{ }^{2}=0.76$ for vertical arrays;

e. a significant two-way interaction between encoding condition and serial position, $F(5,75)=7.48, M S E=0.044, p$ $<.001, \eta_{\mathrm{p}}{ }^{2}=0.33$ : a follow-up analysis of simple effects indicated that memory was better in the passive-view than in the pointing condition for the first three serial positions, $F(1,15)=13.44, p=.002, \eta_{\mathrm{p}}{ }^{2}=0.47 ; F(1,15)=7.14, p=$ $.017, \eta_{\mathrm{p}}{ }^{2}=0.32 ; F(1,15)=14.26, p=.002, \eta_{\mathrm{p}}{ }^{2}=0.48$; in contrast, the advantage of the pointing condition for the last two serial positions approached the significance level, $F(1,15)=3.52, p=.080, \eta_{\mathrm{p}}{ }^{2}=0.19$, and $F(1,15)=3.10$, $p=.098, \eta_{\mathrm{p}}{ }^{2}=0.17$.

For seven-item arrays, a repeated 2 (encoding condition: pointing vs. passive view) $\times 3$ (stimulus type: random, vertical, horizontal) $\times 7$ (serial position) ANOVA found a comparable pattern of results. More specifically, the analysis revealed the following:

a. a significant main effect of stimulus type, $F(2,34)=$ $10.25, M S E=0.077, p<.001, \eta_{\mathrm{p}}{ }^{2}=0.41$, indicating that random arrays $(M=0.29)$ were recalled worse than vertical $(M=0.39, p=.022)$ and horizontal arrays $(M=0.41, p$ $=.002)$, with no difference between the two symmetrical arrays $(p=1.00)$;

b. a significant main effect of serial position, $F(6,102)=$ 8.17, $M S E=0.116, p<.001, \eta_{\mathrm{p}}{ }^{2}=0.35$ : post hoc comparisons, with the Bonferroni adjustment, demonstrated both a primacy effect, with the first location being recalled better than the second, third, fourth, and fifth locations ( $p$ $<.001, p<.001, p<.001, p=.019)$, and a recency effect, with the seventh (last) position being recalled better than the sixth and fifth locations $(p=.031$ and $p=.002$, respectively; the differences with the fourth and third locations approached the significance level: $p=.082$ and $p=$ .062 , respectively);

c. a significant two-way interaction between stimulus type and serial position, $F(12,204)=2.15, M S E=0.040, p=$
$.016, \eta_{\mathrm{p}}{ }^{2}=0.13$ : a follow-up analysis of simple effects revealed that the effect of serial position was more pronounced with random than with vertical and horizontal arrays, although it reached the significance level in all conditions $-F(6,12)=16.60, p<.001, \eta_{\mathrm{p}}{ }^{2}=0.91$ for random arrays, $F(6,12)=7.47, p=.003, \eta_{\mathrm{p}}{ }^{2}=0.82$ for vertical arrays, and $F(6,12)=6.31, p=.006, \eta_{\mathrm{p}}{ }^{2}=0.79$ for horizontal arrays;

d. a significant two-way interaction between encoding condition and serial position, $F(6,102)=15.71, M S E=$ $0.041, p<.001, \eta_{\mathrm{p}}{ }^{2}=0.33$ : a follow-up analysis of simple effects indicated that memory was better in the passiveview than in the pointing condition for the first three serial positions, $F(1,15)=24.46, p<.001, \eta_{\mathrm{p}}{ }^{2}=0.62 ; F(1,15)$ $=20.58, p<.001, \eta_{\mathrm{p}}{ }^{2}=0.57 ; F(1,15)=14.29, p=.002$, $\eta_{\mathrm{p}}{ }^{2}=0.48$, whereas it was better in the pointing than in the passive-view condition for the seventh, sixth, and fifth serial positions, $F(1,15)=8.72, p=.010, \eta_{\mathrm{p}}{ }^{2}=0.36$; $F(1,15)=5.29, p=.036, \eta_{\mathrm{p}}{ }^{2}=0.26 ; F(1,15)=6.76, p$ $=.020, \eta_{\mathrm{p}}{ }^{2}=0.31$, respectively.

To summarize, Experiment 1 found several interesting results. First, symmetrical arrays were recalled better than random arrays, suggesting that participants were able to exploit the structural properties of vertical and horizontal patterns to facilitate their reconstruction from memory (Kemps, 2001; Pieroni et al., 2011; Rossi-Arnaud et al., 2006; Rossi-Arnaud et al., 2012). Second, for item memory, the main effect of the encoding condition approached the significance level with six-item arrays, confirming that, when instructions are blocked (i.e., when participants point to or passively view all the squares in a given trial), movement has an negative impact on spatial memory (Dodd \& Shumborski, 2009; Rossi-Arnaud et al., 2012; Rossi-Arnaud et al., 2015). An overall advantage for the passive-view condition was also obtained on order memory (again limited to six-item arrays), supporting the conclusion that, contrary to theoretical expectations (Dodd \& Shumborski, 2009, p. 1246), pointing toward the target locations hinders the recall of their order of presentation (Spataro et al., 2015). Third, echoing the findings reported by Spataro et al. (2015), the effects of pointing on order memory varied as a function of serial position, being negative for the initial and central locations, but null or positive for the final ones - with the latter facilitatory influence being particularly evident in the case of symmetrical seven-item arrays (see Fig. 2). Finally, the fact that the interaction between encoding condition and stimulus type was never significant demonstrates that pointing movements reduced the recall of both symmetrical and random arrays, consistent with the claim that movement might impair the use of chunking (axis-based) strategies (RossiArnaud et al., 2012; Rossi-Arnaud et al., 2015). 


\section{Experiment 2}

Experiment 2 sought to replicate the set of findings obtained in Experiment 1 but using longer arrays composed of eight or nine items. Previous data with eight-item arrays (Spataro et al., 2015) suggest that the effect of pointing might be different with larger arrays. To account for these findings, Spataro et al. (2015) proposed that when array size increases, participants might favor the use of a chunking strategy in both the passive-view and pointing conditions (Ridgeway, 2006), thus reducing the negative effects of pointing movements. Experiment 2 provides an additional test of this hypothesis, by using symmetrical configurations - which should increase the reliance upon chunking processes (Rossi-Arnaud et al., 2006; Rossi-Arnaud et al., 2012).

\section{Method}

Participants A different sample of 16 students of the University Sapienza of Rome volunteered to participate in Experiment 2. They were five males and 11 females, with a mean age of 23.5 years $(S D=1.6)$, and normal or corrected-tonormal vision.

Stimuli The stimuli were the same 60 arrays used in Experiment 1, with the exception that the number of to-berecalled squares (always appearing in red) was increased to eight or nine. As in Experiment 1, the order of presentation of the red squares within each array was completely random.

Design and procedure Experiment 2 followed a completely repeated 2 (array size: eight and nine items) $\times 2$ (encoding condition: pointing vs. passive view) $\times 3$ (stimulus type: random, vertical, horizontal) design. The procedure was identical to that illustrated for Experiment 1.

\section{Results and discussion}

Item memory As in Experiment 1, item memory was analyzed separately for eight- and nine-item arrays (see Table 2). Regarding eight-item arrays, the mean numbers of locations correctly recalled, irrespective of the order in which they presented at encoding, were submitted to a completely repeated 2 (encoding condition: pointing vs. passive view) $\times 3$ (stimulus type: random, vertical, horizontal) $\times 8$ (serial position) ANOVA, which revealed the following:

a. a significant main effect of stimulus type, $F(2,30)=$ $30.25, M S E=0.054, p<.001, \eta_{\mathrm{p}}{ }^{2}=0.67$, indicating that random arrays $(M=0.54)$ were recalled worse than
Table 2 Experiment 2: Mean proportions of items correctly recalled, as a function of encoding condition, array size and stimulus type. Standard deviations are reported in parentheses

\begin{tabular}{|c|c|c|c|c|}
\hline & \multicolumn{2}{|c|}{ Passive-view condition } & \multicolumn{2}{|c|}{ Pointing condition } \\
\hline & 8-item & 9-item & 8-item & 9-item \\
\hline \multicolumn{5}{|c|}{ Vertical Arrays } \\
\hline Position 1 & $0.88(0.24)$ & $0.82(0.19)$ & $0.78(0.19)$ & $0.76(0.26)$ \\
\hline Position 2 & $0.85(0.24)$ & $0.81(0.26)$ & $0.78(0.23)$ & $0.65(0.27)$ \\
\hline Position 3 & $0.87(0.16)$ & $0.72(0.24)$ & $0.72(0.21)$ & $0.65(0.30)$ \\
\hline Position 4 & $0.83(0.13)$ & $0.65(0.23)$ & $0.67(0.20)$ & $0.58(0.25)$ \\
\hline Position 5 & $0.68(0.27)$ & $0.55(0.29)$ & $0.56(0.29)$ & $0.53(0.31)$ \\
\hline Position 6 & $0.58(0.29)$ & $0.47(0.27)$ & $0.57(0.27)$ & $0.50(0.28)$ \\
\hline Position 7 & $0.56(0.24)$ & $0.58(0.30)$ & $0.62(0.26)$ & $0.58(0.27)$ \\
\hline Position 8 & $0.52(0.28)$ & $0.56(0.22)$ & $0.67(0.26)$ & $0.63(0.27)$ \\
\hline Position 9 & - & $0.58(0.35)$ & - & $0.65(0.27)$ \\
\hline \multicolumn{5}{|c|}{ Horizontal arrays } \\
\hline Position 1 & $0.85(0.13)$ & $0.82(0.19)$ & $0.76(0.26)$ & $0.71(0.20)$ \\
\hline Position 2 & $0.77(0.24)$ & $0.76(0.25)$ & $0.67(0.25)$ & $0.60(0.29)$ \\
\hline Position 3 & $0.75(0.25)$ & $0.56(0.31)$ & $0.62(0.30)$ & $0.60(0.27)$ \\
\hline Position 4 & $0.70(0.23)$ & $0.62(0.22)$ & $0.65(0.25)$ & $0.58(0.35)$ \\
\hline Position 5 & $0.61(0.24)$ & $0.57(0.27)$ & $0.57(0.25)$ & $0.52(0.28)$ \\
\hline Position 6 & $0.46(0.21)$ & $0.43(0.22)$ & $0.56(0.32)$ & $0.48(0.25)$ \\
\hline Position 7 & $0.38(0.21)$ & $0.42(0.19)$ & $0.50(0.32)$ & $0.41(0.27)$ \\
\hline Position 8 & $0.46(0.33)$ & $0.57(0.28)$ & $0.58(0.27)$ & $0.51(0.24)$ \\
\hline Position 9 & - & $0.66(0.25)$ & - & $0.72(0.22)$ \\
\hline \multicolumn{5}{|c|}{ Random arrays } \\
\hline Position 1 & $0.82(0.20)$ & $0.76(0.19)$ & $0.75(0.23)$ & $0.63(0.26)$ \\
\hline Position 2 & $0.68(0.19)$ & $0.71(0.24)$ & $0.65(0.31)$ & $0.63(0.26)$ \\
\hline Position 3 & $0.73(0.18)$ & $0.52(0.30)$ & $0.65(0.24)$ & $0.53(0.27)$ \\
\hline Position 4 & $0.50(0.17)$ & $0.60(0.21)$ & $0.46(0.28)$ & $0.48(0.26)$ \\
\hline Position 5 & $0.46(0.25)$ & $0.43(0.16)$ & $0.38(0.23)$ & $0.43(0.16)$ \\
\hline Position 6 & $0.33(0.22)$ & $0.42(0.20)$ & $0.45(0.23)$ & $0.46(0.23)$ \\
\hline Position 7 & $0.36(0.23)$ & $0.41(0.21)$ & $0.45(0.27)$ & $0.41(0.25)$ \\
\hline Position 8 & $0.43(0.23)$ & $0.51(0.20)$ & $0.51(0.29)$ & $0.61(0.23)$ \\
\hline Position 9 & - & $0.62(0.26)$ & - & $0.72(0.21)$ \\
\hline
\end{tabular}

horizontal $(M=0.62, p=.002)$ and vertical arrays $(M=$ $0.70, p<.001)$; in addition, horizontal arrays were recalled worse than vertical arrays $(p=.002)$ - see Rossi-Arnaud et al. (2006) for similar evidence showing that the advantage of vertical over horizontal configurations occurs only when using supraspan arrays.

b. a significant main effect of serial position, $F(7,105)=$ $16.87, M S E=0.089, p<.001, \eta_{\mathrm{p}}{ }^{2}=0.53$ : post hoc comparisons, with the Bonferroni adjustment, demonstrated a primacy effect, with the first location being recalled better 
than fourth to eighth locations $(p=.001, p<.001, p<$ $.001, p=.001$, respectively), but no recency effect (the last position was recall no better than the seventh to second positions: $p=1.00, p=1.00, p=1.00, p=1.00, p=$ $.30, p=.31)$;

c. a significant two-way interaction between encoding condition and serial position, $F(7,105)=5.32, M S E=0.040$, $p<.001, \eta_{\mathrm{p}}{ }^{2}=0.26$ : a follow-up analysis of simple effects indicated that the advantage of the passive-view condition was significant for the third position, $F(1,15)=10.05, p=$ $.006, \eta_{\mathrm{p}}{ }^{2}=0.40$, and approached the significance level for the fourth position, $F(1,15)=4.03, p=.063, \eta_{\mathrm{p}}{ }^{2}=0.21$; in contrast, the advantage of the pointing condition was significant for the last position, $F(1,15)=10.74, p=.005$, $\eta_{\mathrm{p}}{ }^{2}=0.042$, and approached the significance level for the second to last position, $F(1,15)=3.40, p=.085, \eta_{\mathrm{p}}{ }^{2}=$ 0.19 .

For nine-item arrays, a similar 2 (encoding condition: pointing vs. passive view) $\times 3$ (stimulus type: random, vertical, horizontal $) \times 9$ (serial position) ANOVA found the following:

a. a significant main effect of stimulus Type, $F(2,30)=6.32$, $M S E=0.067, p=.005, \eta_{\mathrm{p}}{ }^{2}=0.30$, indicating that random arrays $(M=0.55)$ were recalled worse than vertical arrays $(M=0.63, p=.006)$;

b. a significant main effect of serial position, $F(8,120)=$ $8.03, M S E=0.119, p<.001, \eta_{\mathrm{p}}{ }^{2}=0.35$ : post hoc comparisons, with the Bonferroni adjustment, demonstrated both a primacy effect, with the first location being recalled better than third to seventh locations ( $p=.001, p=.045, p$ $<.001, p<.001, p=.001)$, and a recency effect, with the last position being recalled better than the sixth and seventh positions $(p=.044$ and $p=.014)$;

c. a significant two-way interaction between encoding condition and serial position, $F(8,120)=2.19, M S E=0.052$, $p=.032, \eta_{\mathrm{p}}{ }^{2}=0.13$ : a follow-up analysis of simple effects indicated that the advantage of the passive-view condition was significant for the first two serial positions, $F(1,15)=$ $5.40, p=.035, \eta_{\mathrm{p}}{ }^{2}=0.26$, and $F(1,15)=10.43, p=.006$, $\eta_{\mathrm{p}}{ }^{2}=0.241$, and approached the significance level for the fourth position, $F(1,15)=4.31, p=.056, \eta_{\mathrm{p}}{ }^{2}=0.22$.

Order memory Order memory was also analyzed separately for eight- and nine-item arrays (see Fig. 3). For eight-item arrays, the proportions of items recalled in their correct serial positions were submitted to a completely repeated 2 (encoding condition: pointing vs. passive-view) $\times 3$ (stimulus type: random, vertical, horizontal $) \times 8$ (serial position) ANOVA, which showed: a. a significant main effect of encoding condition, $F(1,15)=$ $10.98, M S E=0.070, p=.005, \eta_{\mathrm{p}}{ }^{2}=0.42$, indicating that participants recalled more locations in the passive-view (no move) $(M=0.38)$ than in the pointing (move) condition $(M=0.32)$;

b. a significant main effect of stimulus type, $F(2,30)=$ $16.05, M S E=0.069, p<.001, \eta_{\mathrm{p}}{ }^{2}=0.52$, indicating that vertical arrays $(M=0.42)$ were recalled better than horizontal $(M=0.34, p=.005)$ and random arrays $(M=0.29$, $p=.001)$, with no difference between the two symmetrical arrays $(p=.12)$;

c. a significant main effect of serial position, $F(7,105)=$ $18.00, M S E=0.112, p<.001, \eta_{\mathrm{p}}{ }^{2}=0.55$ : post hoc comparisons with the Bonferroni adjustment demonstrated a strong primacy effect, with the first location being recalled better than the second to sixth locations ( $p=.001, p<$ $.001, p<.001, p<.001, p<.001, p=.002)$, and a small recency effect, since the last location tended to be recalled better than the second and third to last locations $(p=.058$ and $p=.069)$.

d. a significant two-way interaction between encoding condition and serial position, $F(7,105)=6.56, M S E=0.050$, $p<.001, \eta_{\mathrm{p}}{ }^{2}=0.30$ : a follow-up analysis of simple effects indicated that memory was better in the passive-view than in the pointing condition for the first five serial positions, $F(1,15)=7.60, p=.015, \eta_{\mathrm{p}}{ }^{2}=0.33 ; F(1,15)=8.01, p=$ $.013, \eta_{\mathrm{p}}{ }^{2}=0.34 ; F(1,15)=54.69, p<.001, \eta_{\mathrm{p}}{ }^{2}=0.78$; $F(1,15)=5.41, p=.034, \eta_{\mathrm{p}}{ }^{2}=0.26 ; F(1,15)=4.87, p=$ $.043, \eta_{\mathrm{p}}{ }^{2}=0.25$, whereas it was better in the pointing than in the passive-view condition for the last serial position, $F(1,15)=5.20, p=.038, \eta_{\mathrm{p}}^{2}=0.26$.

Likewise, for nine-item arrays, a 2 (encoding condition: pointing vs. passive view) $\times 3$ (stimulus type: random, vertical, horizontal $) \times 9$ (serial position) repeated ANOVA showed:

a. a significant main effect of serial position, $F(8,120)=$ 7.33, $M S E=0.186, p<.001, \eta_{\mathrm{p}}{ }^{2}=0.33$ : post hoc comparisons, with the Bonferroni adjustment, demonstrated a strong primacy effect, with the first location being recalled better than the second to sixth locations ( $p=.003, p<$ $.001, p=.001, p<.001, p<.001$; the difference between the first and sixth positions approached the significance level: $p=.054$ ), and a robust recency effect, with the last location being recalled better than the eight, seventh and sixth locations $(p=.022, p<.001, p=.007)$;

b. a significant two-way interaction between encoding condition and serial position, $F(8,120)=6.56, M S E=0.050$, $p<.001, \eta_{\mathrm{p}}{ }^{2}=0.30$ : a follow-up analysis of simple effects indicated that memory was better in the passive-view than in the pointing condition for the first, second and fourth positions, $F(1,15)=6.71, p=.020, \eta_{\mathrm{p}}{ }^{2}=0.31 ; F(1,15)=$ 
Order Memory - Random Arrays

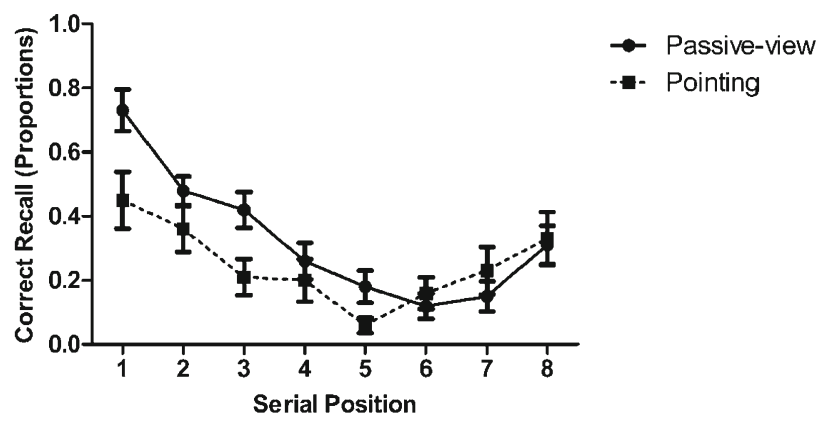

Order Memory - Horizontal Arrays

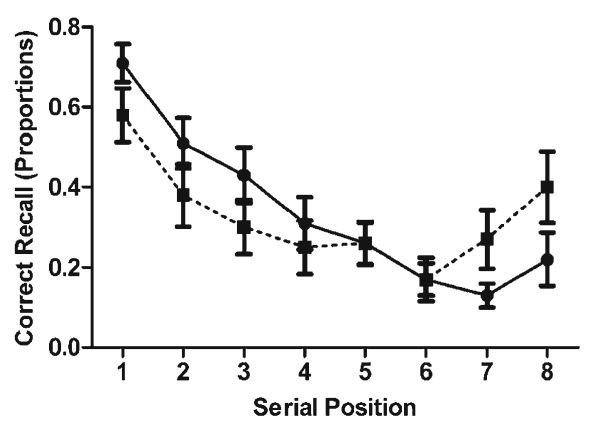

Order Memory - Vertical Arrays

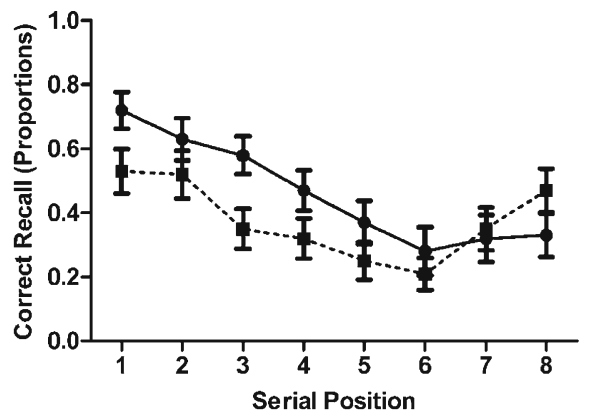

Passive-view Pointing
Order Memory - Random Arrays

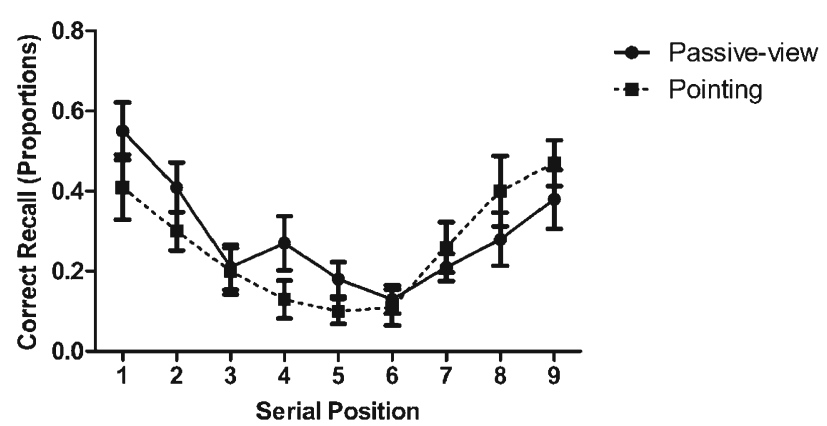

Order Memory - Horizontal Arrays

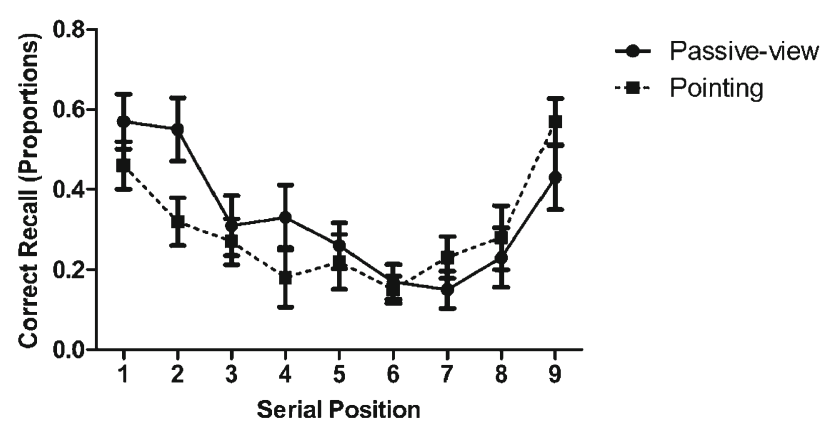

Order Memory - Vertical Arrays

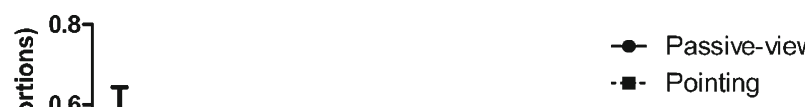

Fig. 3 Experiment 2: Mean proportions of items recalled in their correct serial positions for 8eight- and nine-item arrays, as a function of stimulus type and encoding condition. Bars represent standard errors

$17.40, p=.001, \eta_{\mathrm{p}}{ }^{2}=0.53 ; F(1,15)=10.80, p=.005, \eta_{\mathrm{p}}^{2}$ $=0.42$, whereas it was better in the pointing than in the passive-view condition for the last two serial positions, $F(1,15)=6.35, p=.024, \eta_{\mathrm{p}}^{2}=0.29$, and $F(1,15)=$ $6.60, p=.021, \eta_{\mathrm{p}}{ }^{2}=0.31$.

Overall, the results of Experiment 2 were comparable to those obtained in Experiment 1. Specifically, we replicated the significant interaction between encoding condition and serial position, providing further support for a reversal of the negative effects of pointing on the final serial positions. At the same time, there were also interesting differences. In the item analysis, in particular, the overall advantage of the passiveview condition (over the pointing condition) never reached the significance level, consistent with the notion that the negative impact of pointing movements on VSWM might be load dependent (i.e., might decrease in longer arrays; Chum et al., 2007; Rossi-Arnaud et al., 2012; Rossi-Arnaud et al., 2015).

\section{General discussion}

Over two experiments, we investigated the effects of pointing movements on the item and order recall of symmetrical (vertical and horizontal) and random arrays containing six and seven items (Experiment 1) or eight and nine items (Experiment 2). The first aim was to further analyze the interaction between encoding condition and serial position previously reported by Spataro et al. (2015). As expected, pointing movements impaired the recall of the initial and central 
positions, thus replicating and generalizing Spataro et al.'s (2015) findings. In addition, two novel results of the present study were that (a) the negative impact of pointing movements attenuated to nonsignificance or even reversed into a positive advantage when recalling the final positions of studied arrays and (b) the effects of pointing (both negative and positive) were not restricted to random arrays, but extended to vertically and horizontally symmetric arrays (see Figs. 2 and 3). Before considering the implications of these results, it is worth discussing the potentially confounding roles of two methodological aspects of our experiments. First, the general lower performance in the pointing condition could be explained, at least in part, by the fact that the hand of the participants occluded part of the array during the presentation of the to-beremembered squares. Although difficult to rule out, this hypothesis would exclusively predict impaired performance in the pointing condition, and therefore has inherent difficulties in explaining the positive effects observed in previous studies (Chum et al., 2007; Dodd \& Shumborski, 2009) and in the last serial positions in the current two experiments. Second, we already mentioned that presentation was blocked by condition, so that the passive-view trials were always performed before the pointing trials. We do not believe, however, that this factor had an unduly influence on our conclusions, since similar results (with random arrays) were obtained in the study by Spataro et al. (2015), in which the order of presentation of the two conditions was counterbalanced across participants; in addition, Rossi-Arnaud et al. (2012) showed that the negative effects of pointing on recognition memory were only significant when participants pointed to all stimuli in the first block: thus, if anything, the current order should reduce the negative impact of pointing movements.

Showing that pointing has opposite consequences on the recall of the initial and final positions of a spatial sequence is important, because it constrains the evaluation of alternative theoretical explanations. We have previously mentioned that the VSWM model proposed by Logie (1995) could account for the negative effects of pointing by assuming that the spatial coordination required by hand movements engages the inner scribe, which would be therefore unavailable (or less available) to rehearse the locations encoded during the study phase. Clearly, this hypothesis predicts that pointing movements should impair memory for all serial positions to the same extent, and thus cannot adequately explain the positive influence of pointing on the final items. One partial solution would be to assume that rehearsal processes are more important for the recall of the initial and central items than for the recall of the final items. In this respect, Tan and Ward (2008) found that participants in an immediate serial recall task rehearsed in a cumulative forward order up to Serial Position 4, after which the amount of rehearsal decreased substantially. If the rehearsal mechanisms provided by the inner scribe are not essential for the memorization of final items, then the visuospatial interference produced by pointing movements should be minimal on these positions.

An alternative explanation stems from the notion that planning and implementing target-directed movements require general-purpose executive resources (Spiegel, Koester, \& Schack, 2014), that therefore would be diverted from memorizing the encoded locations (Klauer \& Stegmaier, 1997; Smyth \& Scholey, 1994). Importantly, recent evidence indicates that the request of attention resources varies as a function of serial position. Allen, Baddeley, and Hitch (2014), in particular, examined the impact of a concurrent executive load on memory for three-item sequences of visual objects. Results showed that the disruptive effects of the concurrent load were significant for the first two items of the sequences, but not for the last item. Allen et al. (2014) concluded that VSWM is composed of two separable attentional components: an early component which relies on executive resources, and a late component which allows the relatively privileged and automatic storage of the final items. Assuming that pointing movements require executive resources (Spiegel et al., 2014), the hypothesis of the two attentional components correctly predicts that the degree of memory impairment should decrease as a function of serial position - being largest for locations presented early in the sequence, but minimal (or nonsignificant) for locations presented near the end of the sequence.

While the hypothesis put forward by Allen et al. (2014) can account for the decrease in the negative effects of pointing, it does not inherently predict an advantage of the pointing condition in the recall of the final positions. Such a result is instead consistent with the proposal that encoding a location in space with action (pointing) enriches the visual (allocentric) code with a motor (egocentric) code, which benefits VSWM (Chum et al., 2007; Rossi-Arnaud et al., 2015). In agreement, Ouwehand et al. (2016) have recently reported a set of experiments in which young and older adults encoded a series of natural or artificial pictures presented at one of four locations determined by dividing the screen in four quadrants. At test, the studied pictures were re-presented along with new pictures (foils): participants were required to make an old/new judgment; in addition, when they judged the item to be old, they were also asked to indicate at which of the four locations they had seen the picture during the encoding phase. The results showed that pointing at picture locations during encoding led to better source (spatial) memory than naming the locations or passively observing them. Intriguingly, item memory was not equally facilitated by pointing movements, suggesting that the effect was specific to spatial memory. In more general terms, adding a motor code during the study phase has been shown to improve memory for action phrases (the so-called enactment effect; Engelkamp, 1998; Engelkamp \& Jahn, 2003; Feyereisen, 2009), and gesturing can likewise facilitate the recall of co-occurring speech (Cook, Yip, \& GoldinMeadow, 2010). What is novel about the current study is that 
we have shown that encoding condition and serial position interacted in such a way that the potentially positive influence of pointing on the recall of the initial and central items was completely eliminated and reversed by the negative consequences produced by the simultaneous depletion of attentional resources. Put in other words, we propose that pointing might exert two simultaneous effects on the recall of spatial locations, a positive one linked to the addition of a motor code and a negative one due to the attentional requirements of hand movements. In this framework, the behavioral outcome will change as a function of serial position: When memorization in VSWM is highly dependent on executive resources (i.e., in the case of the initial and central items), the negative effects will prevail, leading to a significant advantage of the passiveview condition; in contrast, when memorization is more automatic (i.e., in the case of the final items; Allen et al., 2014), the positive effects will reemerge, leading to an advantage of the pointing condition.

Besides documenting an inversion of the negative effects of pointing movements on the recall of the final locations, the present results are also important because they contradict the dissociation between item and order memory commonly observed in studies of verbal memory. In fact, a number of encoding conditions (including generation, perceptual interference, word frequency, bizarreness, self-enactment) have been found to increase item memory, while simultaneously impairing order memory (DeLosh \& McDaniel, 1996; Engelkamp \& Dehn, 2000; McDaniel, Einstein, DeLosh, May, \& Brady, 1995; Mulligan, 1999; Nairne, Riegler, \& Serra, 1991). The item-order encoding hypothesis explain these results by proposing that the unusual encoding conditions (e.g., the generate condition, bizarre sentences, low-frequency words) attracts more attentional resources for processing and interpreting the items than does the usual condition (e.g., the read condition, common sentences, highfrequency words). Although this effect enhances encoding of item features, it also draws resources away from the encoding of serial order in the unusual condition, thereby decreasing the performance in tasks that capitalize on serial recall. The present findings might have implications for the item-order encoding hypothesis if one assumes that encoding the locations with pointing movements represents an unusual condition which fosters item memory at the expense of order memory. Our results pose a challenge to this interpretation (and more generally to the item-order hypothesis) since disrupted order memory for the initial and central items did not occur as the by-product of enhanced item memory; if anything, pointing movements disrupted item and order encoding to the same extent in both experiments. A potential explanation for this discrepancy might be that the trade-off between item and order memory holds only when participants must encode meaningful stimuli with preexisting representations. In agreement, Mulligan (2002) failed to support the predictions of the item-order hypothesis when using unfamiliar stimuli such as nonwords and unfamiliar word compounds. By definition, the arrays employed in the current study do not have preexisting representations in long-term memory, and might be consequently less subject to the item-order trade-off observed with meaningful verbal stimuli.

In the previous sections, the negative effects of pointing movements on the recall of the initial and central positions were discussed in the context of the classical model of VSWM proposed by Logie (1995), while the positive effects on the recall of the last positions were assumed to reflect the beneficial influence of dual encoding (Paivio, 1991). However, the present outcomes bear a notable similarity with the results obtained by manipulating modality of presentation in short-term memory (Beaman, 2002). Here, what happens is that the classical modality effect observed in recency - that is, the auditory superiority in the serial recall of final items-is often accompanied by an inverse modality effect at prerecency - that is, a visual superiority in the serial recall of midlist items (Macken, Taylor, Kozlov, Hughes, \& Jones, 2016). The perceptual-motor approach to short-term memory provides a valuable account of these opposite effects by considering the ways in which perceptual objects are formed in the two modalities and how those objects are mapped to speech motor forms to support sequence maintenance and reproduction (Hughes, Chamberland, Tremblay, \& Jones, 2016; Jones, Hughes, \& Macken, 2006). More specifically, this account assumes that (a) compared to the visual modality, the auditory presentation of a sequence leads to a stronger tendency for that sequence to form a coherent object, and (b) the probability of recalling a given item is determined by its being incorporated into a cohesive object. Stimuli that reside near the boundaries of a cohesive sequence become distinctive and highly resolved, whereas stimuli located in the medial positions lose salience - that is, their individual identity becomes less easily addressable (Macken et al., 2016). The important consequence is that medial items have more difficulty in being incorporated into the rehearsal cohort that supports serial recall in the auditory modality (i.e., when they are strongly bound within a coherent sequence) than in the visual modality, leading to lower recall in the former condition; in contrast, the final items have greater chances to be accurately recalled in the auditory than in the visual modality because they acquire special salience in the context of strongly bound sequences (Macken et al., 2016). The perceptual-motor account might provide a viable explanation for the interactions between encoding condition and serial position observed in the present experiments, if one assumes that the path encoding processes recruited by pointing movements lead to the formation of stronger inter-items associations - that is, more cohesive spatial sequences. As a consequence, items that reside at or near the boundaries of the pointed-to sequence are highly resolved and more likely to be included in the rehearsal 
cohort, leading to an advantage of the pointing condition (note that rehearsal in VSWM is thought to be movement based; Logie, 1995). In contrast, items that reside in the interior portion of the pointed-to sequence lose salience and are less likely to be rehearsed, leading to an advantage of the passive-view condition. While additional studies are needed to examine the merits of this hypothesis in accounting for the variable effects of pointing movements on serial memory, it is worth noting that in our experiments a significant advantage of the passiveview condition occurred even in the first serial position. Such a result is difficult to reconcile with the predictions of the perceptual-motor account, because the first item represents a boundary location which should become especially salient in the context of the strongly bounded sequences produced by pointing movements; thus, like the final item, it should be recalled more accurately in the pointing than in the passiveview condition (or the two conditions should result in equivalent recall, as in the study by Macken et al., 2016).

Lastly, consistent with previous evidence (De Lillo, Kirby, \& Poole, 2016; Kemps, 2001; Pieroni et al., 2011; RossiArnaud et al., 2006; Rossi-Arnaudet et al., 2012), we found that order memory was significantly better for symmetrical arrays (both vertical and horizontal) than for random arrays, confirming that our participants took advantage of the structural properties of symmetrical patterns to enhance immediate spatial recall. Most importantly, we showed that pointing movements impaired memory for all types of arrays to the same extent, as indicated by the absence of significant interactions between stimulus type and encoding condition. This finding provides further support for the hypothesis that pointing movements might have a detrimental impact on the use of chunking (axis-based) strategies during the retrieval phase (RossiArnaud et al., 2012; Rossi-Arnaud et al., 2015). The fact that the size of the impairment was comparable on random and symmetric stimuli might suggest that our participants relied on parsing strategies even when reconstructing random arrays. We previously noted that adults tend to reproduce symmetrical sequences by reflection across the axis of symmetry (Bornstein \& Stiles-Davis, 1984); in the case of random sequences, the axis of symmetry cannot be used as a reference point; however, other forms of chunking are still available (e.g., parsing the sequence into smaller groups of three to four items forming a known geometrical shape or a letter; Huntley et al., 2011) and might potentially facilitate the recall of irregular arrays. In agreement, Ridgeway (2006) reported that, in a modified Corsi blocks task, the overall frequency of use of parsing did not differ between structured (spatially separable: 39\%) and nonstructured (nonseparable: $34 \%$ ) sequences.

To conclude, our study advanced current knowledge about the impact of movement-based tasks on VSWM by showing that (a) pointing could both impair and facilitate spatial recall, depending on serial position, and (b) the negative and positive effects of pointing influenced the recall of both random and symmetrical arrays. Taken together, these findings support the view that VSWM involves two separate attentional components (Allen et al., 2014), and demonstrate that pointing benefits serial recall only when the attentional requirements of the retrieval processes decrease (as it is for the recall of the final locations). In addition, they indicate that pointing can have a negative impact on the use of chunking (i.e., axis-based) strategies in the case of symmetrical configurations.

\section{References}

Allen, R. J., Baddeley, A. D., \& Hitch, G. J. (2014). Evidence for two attentional components in visual working memory. Journal of Experimental Psychology: Learning, Memory, and Cognition, 40, 1499-1509.

Baddeley, A. D. (2000). The episodic buffer: A new component of working memory? Trends in Cognitive Sciences, 4, 417-423.

Baddeley, A. (2012). Working memory, theories models and controversy. Annual Review of Psychology, 63, 1-29.

Baddeley, A. D., \& Hitch, G. J. (1974). Working memory. In G. H. Bower (Ed.), Psychology of learning and motivation (Vol. 8, pp. 47-49). New York, NY: Academic Press.

Baddeley, A. D., \& Lieberman, K. (1980). Spatial working memory. In R. S. Nickerson (Ed.), Attention and performance VIII (pp. 521-539). Hillsdale, NJ: Erlbaum.

Beaman, C. P. (2002). Inverting the modality effect in serial recall. The Quarterly Journal of Experimental Psychology, 55, 371-389.

Bornstein, M., \& Stiles-Davis, J. (1984). Discrimination and memory for symmetry in young children. Developmental Psychology, 17, 8286.

Cattaneo, Z., Fantino, M., Silvanto, J., Tinti, C., Pascual-Leone, A., \& Vecchi, T. (2010). Symmetry perception in the blind. Acta Psychologica, 134, 398-402.

Cestari, V., Saraulli, D., Spataro, P., Lega, A., Sciarretta, A., Marques, V. R., \& Rossi-Arnaud, C. (2013). Memory for symmetry and perceptual binding in patients with schizophrenia. Acta Psychologica, 144(3), 594-603.

Chum, M., Bekkering, H., Dodd, M. D., \& Pratt, J. (2007). Motor and visual codes interact to facilitate visuospatial memory performance. Psychonomic Bulletin and Review, 14, 1189-1193.

Cook, S. W., Yip, T. K., \& Goldin-Meadow, S. (2010). Gesturing makes memories that last. Journal of Memory and Language, 63, 465-475.

De Lillo, C., Kirby, M., \& Poole, D. (2016). Spatio-temporal structure, path characteristics, and perceptual grouping in immediate serial spatial recall. Frontiers in Psychology, 7, 1686.

Della Sala, S., Gray, C., Baddeley, A., Allamano, N., \& Wilson, L. (1999). Pattern span: A tool for unwelding visuo-spatial memory. Neuropsychologia, 37, 1189-1199.

DeLosh, E. L., \& McDaniel, M. A. (1996). The role of order information in free recall: Application to the word-frequency effect. Journal of Experimental Psychology: Learning, Memory, and Cognition, 22, $1136-1146$.

Dodd, M. D., \& Shumborski, S. (2009). Examining the influence of action on spatial working memory: The importance of selection. Quarterly Journal of Experimental Psychology, 62, 1236-1247.

Engelkamp, J. (1998). Memory for actions. East Sussex, UK: Psychology Press.

Engelkamp, J., \& Dehn, D. M. (2000). Item and order information in subject-performed tasks and experimenter-performed tasks. 
Journal of Experimental Psychology: Learning, Memory, and Cognition, 26, 671-682.

Engelkamp, J., \& Jahn, P. (2003). Lexical, conceptual and motor information in memory for action phrases: A multi-system account. Acta Psychologica, 113, 147-165.

Feyereisen, P. (2009). Enactment effects and integration processes in younger and older adults' memory for actions. Memory, 17, 374 385.

Hughes, R. W., Chamberland, C., Tremblay, S., \& Jones, D. M. (2016). Perceptual-motor determinants of auditory-verbal serial short-term memory. Journal of Memory and Language, 90, 126-146.

Huntley, J., Bor, D., Hampshire, A., Owen, A., \& Howard, R. (2011). Working memory task performance and chunking in early Alzheimer's disease. The British Journal of Psychiatry, 198, 398-403.

Imbo, I., Szmalec, A., \& Vandierendonck, A. (2009). The role of structure in age-related increases in visuo-spatial working memory span. Psychologica Belgica, 49, 275-291.

Jiang, Y., Olson, I. R., \& Chun, M. M. (2000). Organization of visual short-term memory. Journal of Experimental Psychology: Learning, Memory, and Cognition, 26, 683-702.

Jones, D. M., Hughes, R. W., \& Macken, W. J. (2006). Perceptual organization masquerading as phonological storage: Further support for a perceptual-gestural view of short-term memory. Journal of Memory and Language, 54, 265-281.

Kemps, E. (2001). Complexity effects in visual-spatial working memory: Implication for the role of long-term memory. Memory, 9, 13-27.

Klauer, K. C., \& Stegmaier, R. (1997). Interference in immediate spatial memory: Shifts of spatial attention or central executive involvement? Quarterly Journal of Experimental Psychology, 50, 79-99.

Klauer, K., \& Zhao, Z. (2004). Double dissociations in visual and spatial short-term memory. Journal of Experimental Psychology: General, 133, 355-381.

Lecerf, T., \& de Ribaupierre, A. (2005). Recognition in a visuospatial task: The effect of presentation. European Journal of Cognitive Psychology, 17, 47-75.

Logie, R. H. (1995). Visuo-spatial working memory. Hove, UK: Erlbaum.

Logie, R. H., Zucco, G., \& Baddeley, A. D. (1990). Interference with visual short-term memory. Acta Psychologica, 75, 55-74.

Macken, B., Taylor, J. C., Kozlov, M. D., Hughes, R. W., \& Jones, D. M. (2016). Memory as embodiment: The case of modality and serial short-term memory. Cognition, 155, 113-124.

McDaniel, M. A., Einstein, G. O., DeLosh, E. L., May, C. P., \& Brady, P. (1995). The bizarreness effect: It's not surprising, it's complex. Journal of Experimental Psychology: Learning, Memory, and Cognition, 21, 422-435.

Morris, C. D., Bransford, J. D., \& Franks, J. J. (1977). Levels of processing versus transfer appropriate processing. Journal of Verbal Learning and Verbal Behavior, 16, 519-533.

Mulligan, N. W. (1999). The effects of perceptual interference at encoding on organization and order: Investigating the roles of item-specific and relational information. Journal of Experimental Psychology: Learning, Memory, and Cognition, 25, 54-69.

Mulligan, N. W. (2002). The generation effect: Dissociating enhanced item memory and disrupted order memory. Memory \& Cognition, $30,850-861$.
Nairne, J. S., Riegler, G. L., \& Serra, M. (1991). Dissociative effects of generation on item and order retention. Journal of Experimental Psychology: Learning, Memory, and Cognition, 17, 702-709.

Ouwehand, K., van Gog, T., \& Paas, F. (2016). Effects of pointing compared with naming and observing during encoding on item and source memory in young and older adults. Memory, 24, 1243-1255.

Paivio, A. (1991). Dual coding theory: Retrospect and current status. Canadian Journal of Psychology, 45, 255-287.

Pieroni, L., Rossi-Arnaud, C., \& Baddeley, A. D. (2011). What can symmetry tell us about working memory? In A. Vandierendonck \& A. Szmalec (Eds.), Spatial working memory (pp. 145-159). Hove, UK: Psychology Press.

Quinn, J. G. (1994). Towards a clarification of spatial processing. Quarterly Journal of Experimental Psychology, 47, 465-480.

Quinn, J. G. (2008). Movement and visual coding: The structure of visuospatial working memory. Cognitive Processing, 9, 35-43.

Quinn, J. G., \& Ralston, G. E. (1986). Movement and attention in visual working memory. Quarterly Journal of Experimental Psychology, $38,689-703$

Ridgeway, D. (2006). Strategic grouping in the spatial span memory task. Memory, 14, 990-1000.

Rossi-Arnaud, C., Pieroni, L., \& Baddeley, A. D. (2006). Symmetry and binding in visuo-spatial working memory. Neuroscience, 139, 393-400.

Rossi-Arnaud, C., Pieroni, L., Spataro, P., \& Baddeley, A. D. (2012). Working memory involvement in symmetry encoding: Differences between vertical, horizontal and diagonal configurations. Acta Psychologica, 56, 157-166.

Rossi-Arnaud, C., Spataro, P., \& Longobardi, E. (2012). Effects of pointing on the recall of simultaneous and sequential visuospatial arrays: A role for retrieval strategies? Psychological Research, 76, 699-712.

Rossi-Arnaud, C., Spataro, P., Marques, V. S., \& Longobardi, E. (2015). Pointing towards visuospatial patterns in short-term memory: Differential effects on familiarity- and recollection-based judgments. Canadian Journal of Experimental Psychology, 69, 80-88.

Smyth, M. M., \& Scholey, K. A. (1994). Characteristics of spatial memory span: Is there an analogy to the word length effect, based on movement time? Quarterly Journal of Experimental Psychology, 47, 91-117.

Spataro, P., Marques, V. S., Longobardi, E., \& Rossi-Arnaud, C. (2015). Does pointing facilitate the recall of serial positions in visuospatial working memory? Cognitive Processing, 16, 377-381.

Spiegel, M. A., Koester, D., \& Schack, T. (2014). Movement planning and attentional control of visuospatial working memory: Evidence from a grasp-to-place task. Psychological Research, 78, 494-505.

Tan, L., \& Ward, G. (2008). Rehearsal in immediate serial recall. Psychonomic Bulletin \& Review, 15, 535-542.

Vandierendonck, A., Kemps, E., Fastame, M. C., \& Szmalec, A. (2004). Working memory components of the Corsi blocks task. British Journal of Psychology, 95, 57-79.

Wagemans, J. (1997). Characteristics and models of human symmetry detection. Trends in Cognitive Sciences, 1, 346-352. 